\title{
Effectiveness of Tongue Crib Combination Treating Severe Skeletal Angle Class III Malocclusion in Mixed Dentition
}

\author{
Wenting Zhao ${ }^{1}$, Yan Chen ${ }^{2}$, Hee-Moon Kyung ${ }^{3}$, Jin-Shuai Xu ${ }^{4}$
}

\begin{abstract}
Objective: To evaluate the treatment effects of tongue crib combination for treating severe skeletal Angle class III malocclusion in mixed dentition by X-ray cephalometric analysis.

Materials and methods: A sample of 22 patients with severe skeletal Angle class III malocclusion of deficiency maxilla and overgrown mandible in mixed dentition was prospectively collected and equally divided into two groups. The patients (males 6 and females $5 ;$ mean age $8.35 \pm$ 1.6 years) in the study group were treated with tongue crib combination, and the untreated patients (females 5 , males 6 ; mean age $8.12 \pm 1.3$ years) served as the control group. X-ray cephalometric films were measured before and after treatment for comparing the change of occlusion, maxilla, mandible, and soft tissue. A paired $t$-test was used by SPSS 21.0 statistical software. The intragroup data were compared by using the Wilcoxon test, and intergroup data were compared by using the Mann-Whitney $U$ test $(p<0.05)$.

Results: In the study group, all patients got a favorable facial profile. Anterior and posterior teeth crossbite and upper and lower first molars relationships were improved. In cephalometric measurement, significant changes were noted in the maxillary skeletal component. The significant forward growth of the maxilla exhibited in a statistical increase of SNA, ANS-PNS, Wits appraisal, $p<0.05$. The mandible revealed slightly posterior rotation by no significant decrease in SNB and no change Co-Gn. After 1-year of retention, the changes of the teeth showed self-correction and facial profile improved further. Regarding vertical changes, maintenance of growth was shown a small non-significant increase of FMA, N-Me, and ANS-Me. There is a significant difference from those in the control group $(p<0.05)$.

Conclusion: Tongue crib combination is an effective device for the patients in the growing period with skeletal Angle class III malocclusion by improving the maxillary growth and limiting the mandibular growth.
\end{abstract}

Keywords: Growing period, Skeletal Angle class III malocclusion, Tongue crib combination, X-ray cephalometric analysis.

International Journal of Clinical Pediatric Dentistry (2020): 10.5005/jp-journals-10005-1855

\section{INTRODUCTION}

The incidence of Angle class III malocclusion in a different ethnic group has been published in a large number of studies, ${ }^{1-3}$ it appears to be more common in Asian and Mongolian descents than in white populations. Skeletal Angle's class III malocclusion is characterized by craniofacial and dental disharmony, including a protrusive mandible and mandibular dentition, retrusive maxilla and maxillary dentition ${ }^{4}$ or both. Its treatment and prognosis are considered to be one of the most challenging and perplexing orthodontic endeavors. ${ }^{5}$ The severe dentofacial deformation often appeared in the prepubertal period. Some studies ${ }^{6}$ have considered the main advantage of the early treatment for Angle class III malocclusion is to avoid surgical intervention, or, at least, to reduce the morbidity of the surgery. If the deformation cannot be controlled early, after the stage of a pubertal growth spurt, only the orthodontic camouflage or orthognathic surgery would be chosen. ${ }^{7}$ Other studies ${ }^{8}$ have found that there is no effective evidence that supports the benefits of early treatment.

It is a controversial topic that growth modification is possible and necessary after cephalometric measurement was used in orthodontics. In numerous previous studies, ${ }^{9-11}$ many early functional appliances, such as bionator, chin-cup, and protraction, have been reported to achieve results with varying success for class III malocclusion. However, these treatment methods considered that growth was largely affected by environmental factors and considered only tooth movement. Many new techniques have been attempted to adjust the proportional relationship during craniofacial growth and to decrease unwanted teeth compensation.

During recent decades, a new technique ${ }^{12,13}$ has been gaining popularity. It is the treatment with skeletal anchorage. It has been

\begin{abstract}
1,3 Department of Orthodontics, School of Dentistry, Kyungpook National University, Daegu, South Korea

${ }^{2}$ Department of Orthodontics, Affiliated Hospital of Inner Mongolia Medical College, Hohhot, Inner Mongolia, China

${ }^{4}$ Oral Department, General Hospital of Datong Coal Mine, Datong, Shanxi, China
\end{abstract}

Corresponding Author: Yan Chen, Department of Orthodontics, Affiliated Hospital of Inner Mongolia Medical College, Hohhot, Inner Mongolia, China, Phone: +86 0471 3451219, e-mail: 1336806259@ qq.com

How to cite this article: Zhao W, Chen Y, Kyung H-M, et al. Effectiveness of Tongue Crib Combination Treating Severe Skeletal Angle Class III Malocclusion in Mixed Dentition. Int J Clin Pediatr Dent 2020;13(6): 668-676.

Source of support: Nil

Conflict of interest: None

reported that it produces faster skeletal effects and less unwanted dentoalveolar changes than conventional treatment. Nevertheless, it has been proposed ${ }^{14}$ that skeletal anchorage procedures have possible disadvantages: they conclude more or less invasive procedures to place and subsequently remove the devices, and sometimes they are unstable throughout treatment. Clinicians are hesitant ${ }^{15}$ whether or not the potential advantage of skeletal anchorage is possible with less patient compliance.

The etiology of skeletal class III malocclusion involves two factors: heredity and environment, the later included unfavorable growth, digital habits, and tongue habits. Most dentists know the tongue crib appliance is effective in modifying tongue behavior, ${ }^{16}$ 
especially for open bite over several years. It has been described ${ }^{17}$ to work as an obstacle in non-nutritive sucking and maintaining the tongue in a more backward position, so prevent tongue thrust. The tongue crib was reported ${ }^{18}$ to force the tongue to function in a more posterior and higher position, after observing the tongue movements of patients wearing a palatal crib during deglutition using cinefluorography. Tongue crib obstructed patients' harmful tongue habits, and at the same time, changed muscular activity around the mouth. Nevertheless, tongue crib appliance treating skeletal class III malocclusion has not attracted clinician's attention. Few studies ${ }^{19}$ have evaluated the craniofacial modifications after orthopedic correction by this appliance, so much so that as it has been rarely mentioned in the previous studies. ${ }^{20}$

The present respective study was to evaluate the dentoskeletal effects produced by tongue crib combination for severe skeletal Angle's class III malocclusion patients in the growing period.

\section{Materials and Methods}

In the present prospective study, the patients were allocated into two groups randomly. The samples in the study group consisted of 11 consecutive growing class III malocclusion patients (females 5 , males 6 ; mean age $8.35 \pm 1.6$ years), with protruding chin and similar skeletal and dental deformation. The 11 patients (females 5 , males 6; mean age $8.12 \pm 1.3$ years) in the control group had a similar facial pattern and dentoskeletal characteristics. The participants were selected based on inclusion criteria below: (1) concave facial shape and mandibular protrusion; (2) mixed dentition, anterior teeth, and/or posterior teeth crossbite malocclusion; (3) overjet smaller than $-2 \mathrm{~mm}$; (4) the relationship of upper and lower first molars was mesial; (5) absence of a functional shift of the mandible; (6) ANB angle was negative; (7) Wits appraisal was less than $-2 \mathrm{~mm}$; (8) without previous orthopedic treatment history.

A non-extraction approach was planned for all patients. After a detailed and informative explanation of the treatment procedures to all participants, signed informed consent and assent forms were obtained from the parents. The patients in the study group received tongue crib combination treatment in the orthodontic department, Affiliated Hospital, Inner Mongolia Medical University. The patients in the control group would start their orthopedic treatment a halfyear later.

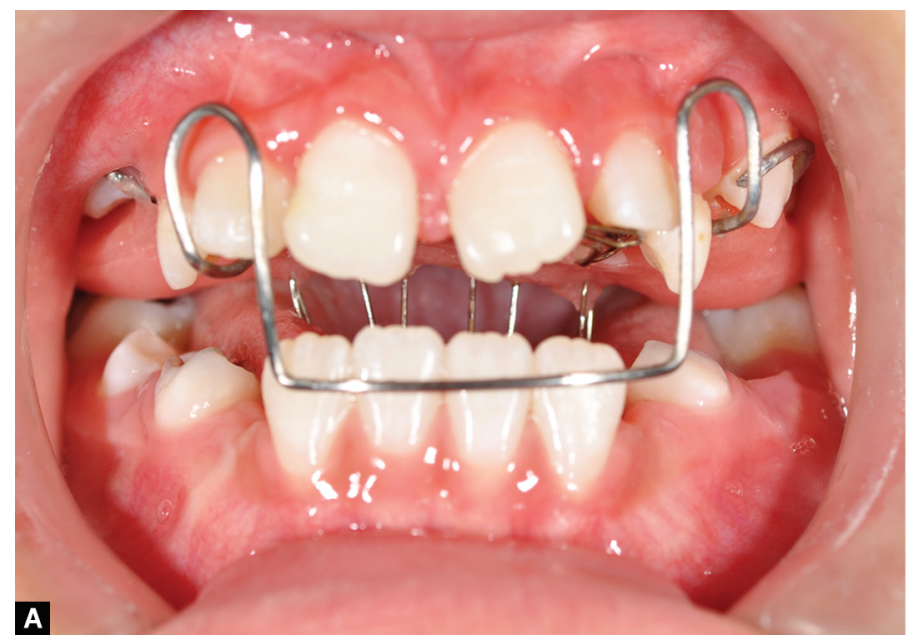

\section{Treatment Protocol}

All the patients in the study group were treated with a tongue crib combination, which is a removable appliance composed of two to three palatal cribs, Adams' clasps on the maxillary permanent first molars, a reverse labials archwire, expander, and acrylic coverage on the palatal region and occlusal pad. The palatal cribs were put on a line between the palatal canine and first premolar. They were around $15 \mathrm{~mm}$ in height, adjusted in the mouth depending on the palatal height for resisting tongue sticking and not compressing mucosa. The occlusal pad provided oral space and backward lower dentition and was removed after the crossbite was corrected. Reverse labial archwire was put on the middle or the lower anterior teeth, for the patients with excessive protruding chin (Fig. 1).

Patients were instructed to wear the appliance full-time, especially during meals, but not when teeth-brushing. The real amount of appliance wear varied effectively. The expander was activated once every 2 days with one-fourth of a turn in the evening until no teeth crowding was seen. The expender was only used for the patients with maxillary teeth crowding or narrow maxilla.

\section{Study Methods}

After the treatment protocol was determined, the tongue crib combination was adorned. The patients were asked to visit every 4 weeks. After crossbite was corrected around 2-4 months, the occlusion pad was removed successively, until it was removed totally. Then, reverse labial archwire was removed. The palatal cribs were maintained for day and night at least one-half of a year. Then, the appliance was only used at night until the patient tongue habit disappeared. The treatment effects were assessed in three stages. The first stage was when the anterior teeth crossbite was initially relieved. The second stage was when the positive overjet was greater than $2 \mathrm{~mm}$ and the occlusion pad was totally removed. The third stage was after 1-year of retention.

\section{Cephalometric Analysis}

Lateral cephalograms with centric occlusion, a reposed lip, and natural head position in the study group were taken at the beginning (ST0) and the end (ST1) of active treatment, and after 1-year of retention (ST2) (Fig. 2) and before (CT0) and after (CT1) during observations in the control group. They were taken by the

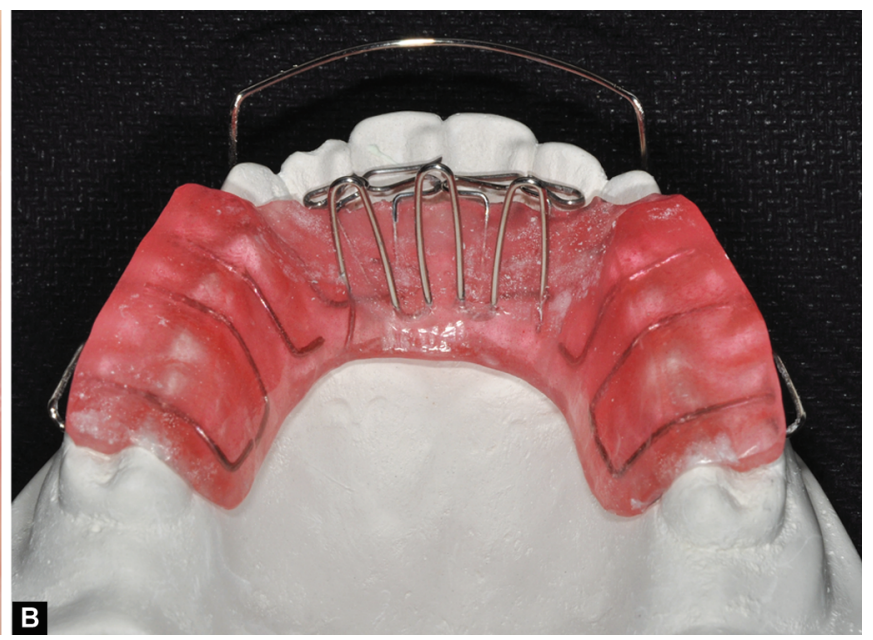

Figs 1 A and B (: A) Image of the appliance was installed in the mouth of a patient; (B) Finished appliance installed on the plastic model 

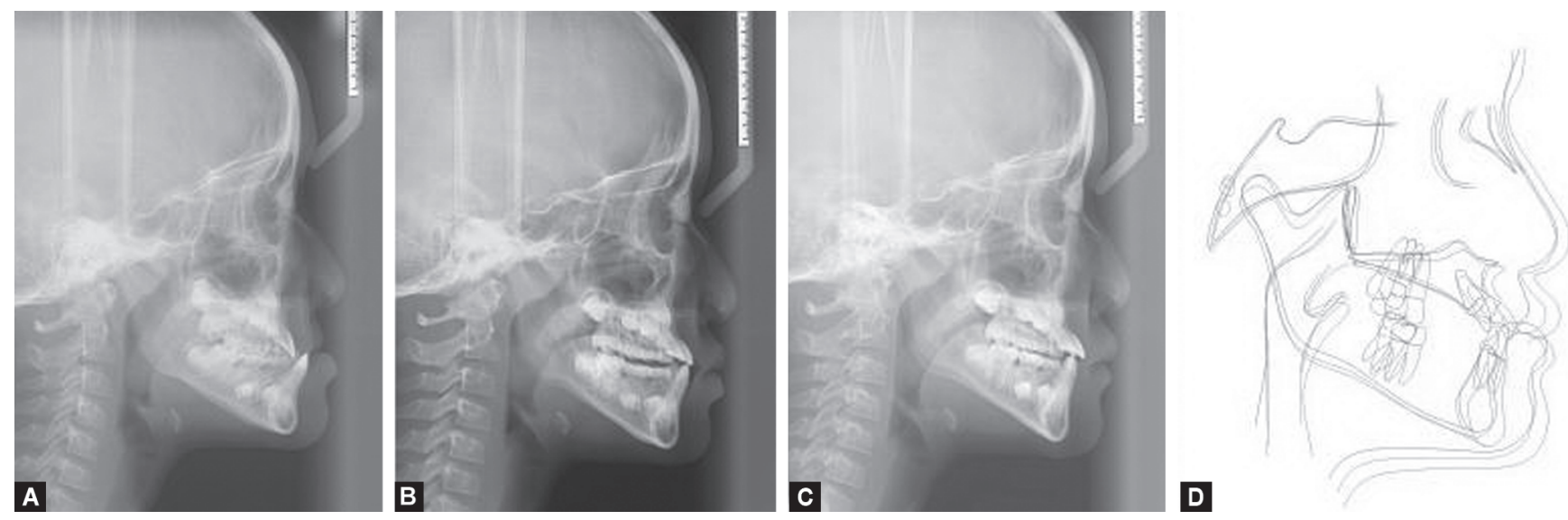

Figs 2A to D: (A) Pretreatment cephalogram; (B) Posttreatment cephalogram; (C) Cephalogram after 1-year of retention in one patient in the study group; (D) Cephalometric superimposition from before, after treatment, and after 1-year of retention cephalogram

equipment of an X digital machine (KAVO EXAM PLUS) before and after the treatment or observation. All customized digitization cephalograms were analyzed by Viewbox 3.0 (CLINVIEW 10.2.6). The analyzes comprised of Stainer, Downs, Tweed, Rickettes, Wits, and Beijing Dental School, generated 34 variables, 22 angular and 12 linear, for each tracing. The skeletal measurements included SNA, SNB, ANB, MP-SN, PP-MP, Y-axis angle; dental measurements included U1-SN, U1-NA, Wits appraisal, L1-MP, L1-NB, upper and lower incisor overjet, and the relationship between upper and lower permanent first molars. Soft tissue measurements composed of facial angle, nose-lip angle, protrusion distance of upper and lower lips. A magnification factor of $9.5 \%$ was applied. All cephalograms were traced and superimposed by the same operator. The S-N plane was introduced as the horizontal reference plane for estimating vertical changes.

\section{Error of Method}

All measurements were repeated 2 weeks later by one operator to determine the level which is in the initial method error. Intraclass coefficient correlation and Bland-Altman were introduced to estimate the intra-observer reliability, which varied from 0.954 for SNB to 0.988 for SN-U1. These values reflected a high level of intra-observer agreement. Linear measurement errors were in the interval of $0.3 \pm 0.8 \mathrm{~mm}$, and angular measurements averaged 0.4 \pm 0.6 . Therefore, the initial set of measurements was introduced in the present research.

\section{Statistical Analysis}

Homogeneity and malocclusion between the two groups allowed comparisons without annualizing the data. As an exploratory analysis by the Shapiro-Wilk test, the data did not reflect the normal distribution. Thus, non-parametric statistics were introduced. Significant differences in the cephalometric variables between the groups of treatment vs control were tested by means of the Mann-Whitney $U$-test. The Wilcoxon test was used for intragroup comparison. All statistical computations were performed using statistical software SPSS 21.0 (SPSS Inc., Chicago, IL, USA). $p<0.05$ was considered to show significant statistical differences.

\section{Results}

\section{Comparison of the Age, Treatment Duration, and Observation Period According to the Stage, between the Treatment and Control Groups}

In the present study, the power of the sample size of the two groups was found to be $95 \%$. This distribution of the participants did not affect the homogeneity of the sample in this study, from the aspects of chronological age and sex. Clinically, anterior teeth crossbite of the patients was corrected and lateral facial shape was initially improved in around 4 weeks. The positive overjet of the anterior teeth was totally set up and posterior teeth occlusion was built in $24 \pm 12.23$ weeks in the study group. Generally, after treatment with the tongue crib combination, the patients in the study group presented improvement in their facial profile and occlusion, with correction of anterior crossbite, and an improved face shape was seen. After 1-year of retention, facial profile further improved (Fig. 3), and the molar relationship was improved too (Fig. 4). The mean observation period for the patients in the control group was $25 \pm$ 14.76 weeks, and only a small change was observed.

\section{Comparison of the Cephalometric Variables at the Beginning of the Treatment and Observation between Two Groups}

As shown in Table 1, there exists no significant difference in the variables of cephalometric at the ST1 and CT1 stage between these two groups. The results of the measurements indicated that the two groups presented similar clinical characteristics at the baseline of the study (Table 1).

\section{Comparison of the Changes in the Cephalometric Variables between the Two Groups before and after the Treatment/Observation}

As shown in Table 2, compared to the data in the control group, the anteroposterior position of the maxilla revealed significant forward movement of point $A$ in the study group. There was a statistical increase in the angle SNA, and an increase in maxillary length (ANS-PNS). The anteroposterior position of the mandible showed movement downward and backward of point B. There 

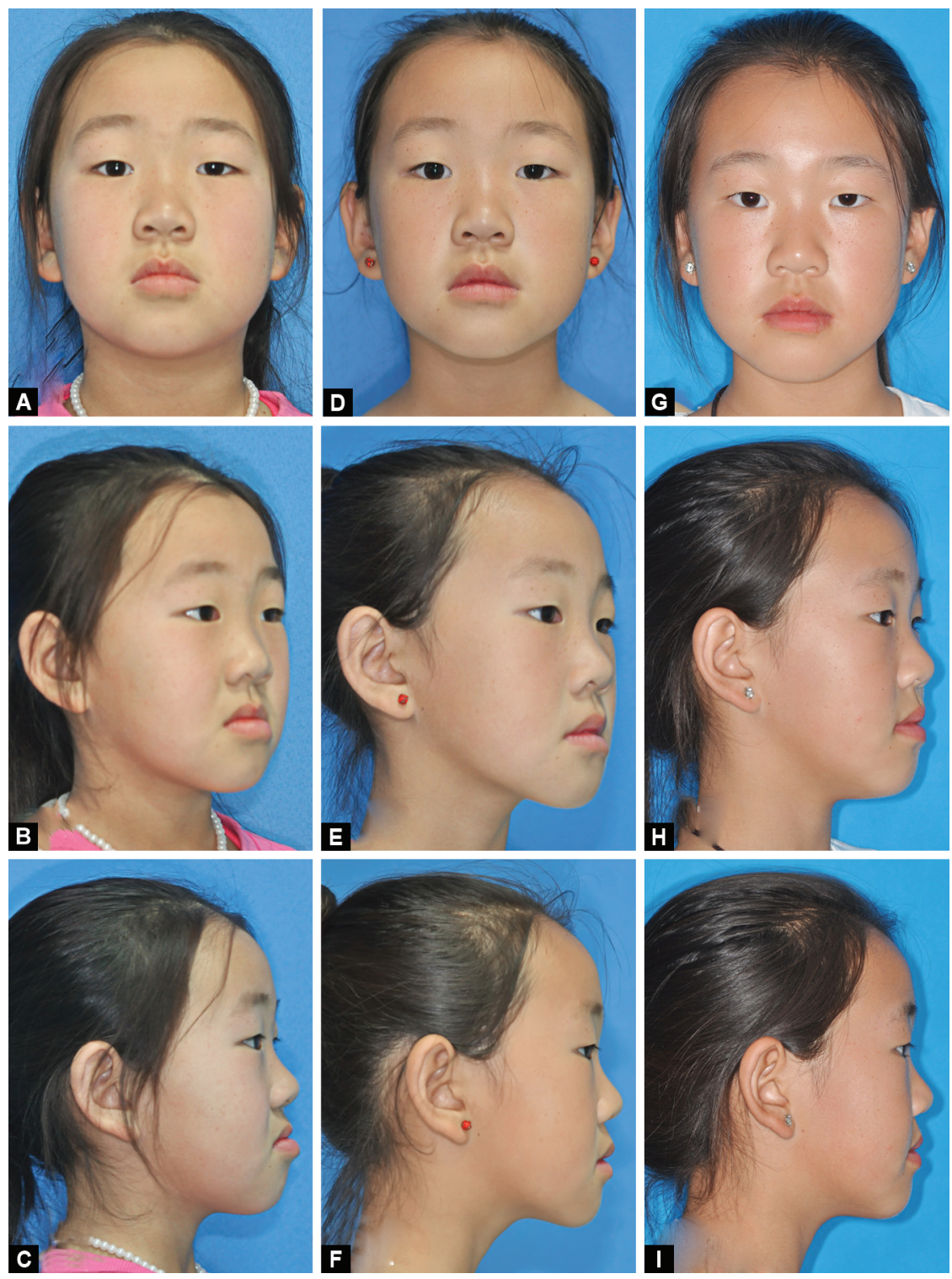

Figs 3A to I: Facial images of a female patient (8.5-year-old) with skeletal class III malocclusion. (A) Facial frontal; (B) Oblique; (C) Profile before treatment; (D) Facial frontal; (E) Oblique; (F) Profile after 5 months of active treatment; (G) Facial fontal; (H) Oblique; (I) Profile after 1-year of retention

was a statistical decrease in the angle SNB in the study group and a slight increase in the control group. The increase of mandibular length (Co-Gn) was not seen in the study group, and a nonsignificant increase was seen in the controlled group. Concerning the relationship between the upper and lower jaw, there was a significant increase in Wits appraisal, ANB, and overjet in the study group. As to the vertical changes, the growth of the frontal face showed a small non-significant increase of FMA, N-Me, and ANS-Me in the two groups. A comparison of the amounts of the dental and soft tissue in the study group revealed an increase in labioversion of the maxillary incisor and perfect soft tissue data (protrusion of the upper lip and retrusion of the lower lip).

From the cephalometric superimposition, both the maxilla and the mandible grew forward and downward in the two groups. In the study group, the sagittal positions of the upper first molars grew forward and downward greater than the lower first molars. Then, the relationship between the upper and lower first molars became more central. In the control group, the sagittal position of the upper and lower first molar remained non-significant changes.

\section{Comparison of the Cephalometric Variables after the Treatment (ST1) and after 1-year of Retention (ST2) in the Study Groups}

As shown in Table 3, the comparison of the cephalometric variables between ST1 and ST2 revealed the dentoskeletal improvement with the special retention of Harley retainer with tongue crib. Comparative analysis of the skeletal changes in the upper and lower jaws showed normal growth in the prepubertal period. Non-significant changes were seen in SNA $\left(+1.51^{\circ}\right)$, Wits appraisals $(+0.14 \mathrm{~mm})$, and SNB $\left(+0.44^{\circ}\right)$. However, the dental changes showed a self-correction. There were significant differences in the increase of overjet $(+3.59 \mathrm{~mm}, p<0.05)$, and the decrease in L1-NB $\left(-0.99^{\circ}\right)$. The relationship between the upper and lower first molars was improved further. 

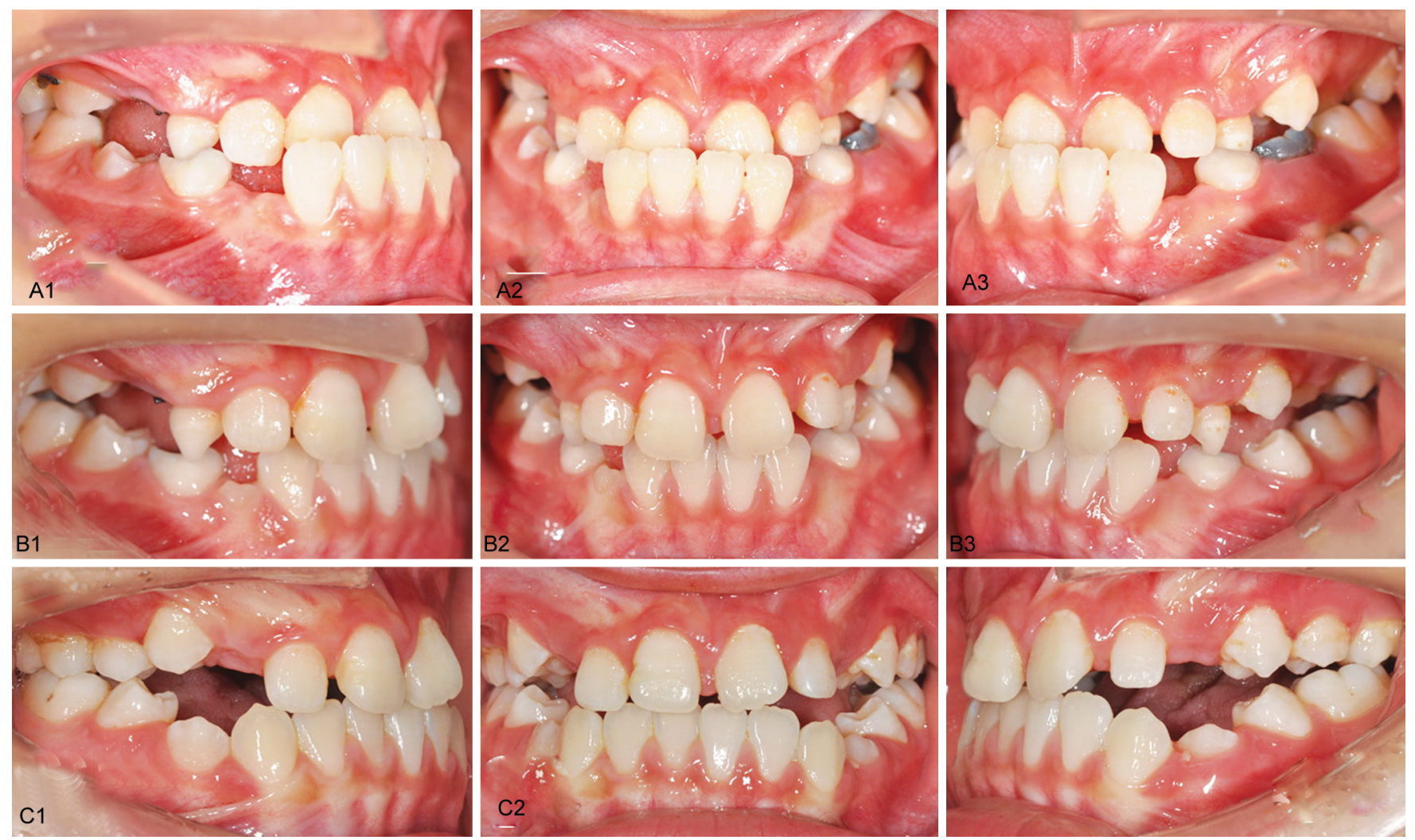

Figs 4A to C: Dental images of a patient: (A1) Intraoral right lateral; (A2) Frontal; (A3) Left lateral view before treatment; (B1) Intraoral right lateral; (B2) Frontal; (B3) Left lateral view after 5-months active treatment; (C1) Intraoral right lateral; (C2) Frontal; (C3) Left lateral view after one-year retention

\section{Discussion}

The present prospective study involved a clinical controlled trial evaluating the effectiveness of the tongue crib combination by treating the patients with skeletal class III malocclusion in the growing period and then comparing with the changes with an untreated group. This research was designed as we found the patients with class III malocclusion that were treated by tongue crib combination got a more favorable face shape clinically than that by other therapies. De Clerck and Proffit ${ }^{21}$ concluded growth modificative of the face was more difficult to obtain than changing tooth movement. The complexity of the challenging skeletal class III malocclusion might require a combination of behavior modification and orthopedic therapies to change the patient's perioral myofunction. Proffit ${ }^{22}$ stated it could be predicted that approximately $80-90 \%$ of malocclusion in which an environmental cause was possible could be treated successfully without relapse and without any therapy directed specifically at altering muscular patterns.

The development of the mandible relies on the tongue and perioral muscles. Exerts strong pressure at frequent intervals during rest and function as the tongue is a powerful muscular organ. Tongue crib can not only obstruct patients' harmful tongue habits, ${ }^{23}$ at the same time, but also change perioral muscular activity. The key point of the appliance design was the vertical height of the tongue crib which played the main role in maintaining mandible backward movement by changing the perioral myofunction and swallowing pattern. The tongue crib's effectiveness, it has been suggested, ${ }^{24}$ is not derived from a dynamic restraint of the tongue, rather than from a redirection of the tongue's position. Tongue cribs induce a change in the position of the tongue action, thus controlling the mandibular muscular movement. The thickness of the occlusal pad was considered to be the optimal choice to control the occlusal vertical height and to change the hyperdivergent mandibular pattern. Tongue crib combination is a changeable device, when the maxilla is narrow and teeth crowding is found, an expansion device should be installed. If the patients have an overgrown mandible, a reverse labial archwire could be designed.

All patients in the study group revealed a significant favorable facial profile after a half-year orthopedic treatment, and their facial shape improved further during the retention period. Their overjet increased obviously with the treatment, from negative to positive, with an average of $+5.83 \mathrm{~mm}(4-10 \mathrm{~mm})$. The main reason for the improvement was due to a maxilla growth forward. The limitation of the mandibular growth and retroclination of the lower incisor played some parts also. A similar amount of overjet improvement after the maxillary anterior replacement was reported in some studies $^{25}$ on a miniplate-anchored face mark.

The outcomes from the cephalometric measurement in the present study revealed significant sagittal facial and skeletal improvements, such as the maxillary advancement (SNA $+2.12^{\circ}$ ) and control of mandibular position (SNB $\left.-1.88^{\circ}\right)$ and intermaxillary sagittal relationship (Wits $+9.15 \mathrm{~mm}$ and $\mathrm{ANB}+4.07^{\circ}$ ) when compared to the control group, although without maxillary protraction. These values were found to be similar to the data in another study ${ }^{26}$ in that an increase in SNA $\left(2.23^{\circ}\right)$, reduction in SNB $\left(-1.33^{\circ}\right)$, and improvement of ANB $\left(+3.81^{\circ}\right)$ and Wits $(+5.44 \mathrm{~mm})$ was found by using miniplates as a skeletal anchorage for maxillary protraction in the group of growing class III patients with maxilla deficiency. They were higher than the findings ${ }^{27}$ reported on SEC III treatment (splint, class III elastics, and chin-cup) in a sample of 
Table 1: The mean ages and cephalometric measurements before treatment/observation in the study and control group ( $n=11$ each group)

\begin{tabular}{|c|c|c|c|c|c|}
\hline \multirow[b]{2}{*}{ Parameter } & \multicolumn{2}{|c|}{ STO } & \multicolumn{2}{|c|}{ CTO } & \multirow[b]{2}{*}{$p$ value } \\
\hline & $x$ & $S D$ & $x$ & $S D$ & \\
\hline Age (years) & 8.35 & 1.6 & 8.12 & 1.3 & 0.612 \\
\hline \multicolumn{6}{|l|}{ Cranial } \\
\hline S-N & 71.12 & 2.34 & 71.06 & 1.43 & 3.42 \\
\hline \multicolumn{6}{|c|}{ Maxilla and mandible } \\
\hline SNA & 75.10 & 1.94 & 77.29 & 5.92 & 3.023 \\
\hline ANS-PNS & 51.96 & 3.16 & 50.47 & 2.48 & 0.045 \\
\hline SN/ANS-PNS & 8.58 & 2.79 & 9.95 & 2.86 & 1.226 \\
\hline SNB & 81.96 & 1.96 & 81.93 & 2.86 & 0.141 \\
\hline SND & 79.54 & 4.67 & 80.25 & 2.31 & 0.241 \\
\hline Co-Gn & 113.23 & 2.35 & 112.67 & 2.44 & 1.063 \\
\hline SN-OP & 15.45 & 3.86 & 14.84 & 2.32 & 5.556 \\
\hline SN-GoGn & 31.65 & 3.77 & 33.91 & 4.14 & 0.086 \\
\hline Y-axil & 69.51 & 4.50 & 69.32 & 4.69 & 0.211 \\
\hline NP-FH & 88.50 & 14.05 & 86.65 & 16.11 & 1.003 \\
\hline ANB & -3.76 & 2.67 & -1.88 & 0.94 & $0.035^{*}$ \\
\hline Convexity & -8.35 & 0.34 & -7.62 & 0.13 & 0.313 \\
\hline MP-FH & 32.22 & 21.21 & 31.12 & 11.81 & 2.304 \\
\hline FMA & 24.86 & 4.15 & 32.43 & 7.75 & 4.215 \\
\hline FMIA & 73.78 & 5.31 & 76.28 & 6.35 & 3.253 \\
\hline IMPA & 81.36 & 6.62 & 73.56 & 7.82 & 0.079 \\
\hline Wits & -13.66 & 2.56 & -6.8 & 3.06 & $0.036^{*}$ \\
\hline Overjet & -4.68 & 2.92 & -3.11 & 1.44 & $0.044^{*}$ \\
\hline $\mathrm{N}-\mathrm{Me}$ & 108.35 & 6.62 & 111.00 & 3.6 & 0.055 \\
\hline ANS-Me & 57.00 & 4.35 & 60.31 & 5.22 & 1.143 \\
\hline \multicolumn{6}{|l|}{ Dental } \\
\hline U1-SN & 95.75 & 7.82 & 85.56 & 6.29 & 1.032 \\
\hline L1-MP & 81.36 & 7.96 & 92.53 & 3.234 & 0.611 \\
\hline U1-NA $\left({ }^{\circ}\right)$ & 26.69 & 3.34 & 30.18 & 3.47 & 3.332 \\
\hline U1-NA (mm) & 7.24 & 0.48 & 4.41 & 0.26 & 0.213 \\
\hline L1-NB $\left(^{\circ}\right)$ & 20.09 & 3.25 & 31.89 & 5.23 & 4.003 \\
\hline L1-NB (mm) & 8.08 & 1.96 & 4.73 & 2.16 & 2.234 \\
\hline U1-L1 & 137.4 & 6.32 & 115.78 & 4.13 & 0.215 \\
\hline Overbite & 5.21 & 2.12 & 4.67 & 1.12 & 3.334 \\
\hline \multicolumn{6}{|l|}{ Soft tissue } \\
\hline FCA & -5.1 & 1.4 & 5.4 & 1.6 & 0.251 \\
\hline NLA & 81.26 & 12.05 & 83.1 & 15.21 & 2.223 \\
\hline UL-E (mm) & -6 & 1.6 & 3 & 1.2 & 0.155 \\
\hline LL-E (mm) & 3 & 0.8 & -2 & 0.3 & 1.107 \\
\hline
\end{tabular}

${ }^{*} p<0.05$ statistically significant difference

25 class III growing patients (SNA $+1.2^{\circ}, \mathrm{SNB}-1.3^{\circ}, \mathrm{ANB}+2.6^{\circ}$, Wits $+3.7 \mathrm{~mm}$ ).

When compared with the control group, the vertical skeletal height revealed no significant differences in the study group. The intermaxillary divergency did not show a change during the treatment. These findings were consistent with the outcomes of chin-cup and skeletal anchorage protraction therapy ${ }^{28,29}$ and suggested that tongue crib combination might minimize the open rotation of mandible in the case of class III malocclusion in a growing period, with the advantageous effects (accompanied by a rotation of the maxilla, which is less closing). Some studies ${ }^{30}$ reported the rotations of the maxilla and mandible often happened in protraction and class III elastics.

The cephalometric superimposition exhibited the growth direction of the maxilla showed downward and forward in both groups, but the mandible's growth speed was slower than that of the maxilla in the study group. Finally, the relationship between the upper and lower first molars intended to be central. Regarding dental relationship improvement, achieving more skeletal growth, in the orthopedic treatment of growing class III patients with an anterior and posterior crossbite, meanwhile without compensatory tooth movement is desirable. However, in a limited orthopedic 
Table 2: Comparison of changes in the lateral cephalometric measurements before and after treatment/observation in the study and control group ( $n=11$ each group)

\begin{tabular}{|c|c|c|c|c|c|c|c|}
\hline \multirow[b]{2}{*}{ Parameter } & \multicolumn{3}{|c|}{ Study group } & \multicolumn{3}{|c|}{ Control group } & \multirow[b]{2}{*}{$p$ value } \\
\hline & $x$ & $S D$ & $p$ value* & $x$ & $S D$ & $p$ value* & \\
\hline \multicolumn{8}{|l|}{ Cranial } \\
\hline $\mathrm{S}-\mathrm{N}$ & 0.55 & 0.23 & 0.612 & 0.51 & 0.64 & 0.263 & 0.616 \\
\hline \multicolumn{8}{|c|}{ Maxilla and mandible } \\
\hline SNA & 2.12 & 1.93 & 3.420 & -0.25 & 0.12 & 1.513 & $0.013^{*}$ \\
\hline ANS-PNS & 1.31 & 1.56 & $0.032^{*}$ & 0.66 & 0.43 & 3.031 & 0.022 \\
\hline SN/ANS-PNS & -0.51 & 1.45 & 0.044 & 0.38 & 0.91 & 0.062 & 0.933 \\
\hline SNB & -1.88 & 2.48 & 0.016 & 0.08 & 0.06 & 0.147 & 0.422 \\
\hline SND & 2.71 & 1.44 & 0.056 & 1.74 & 1.24 & 1.622 & 0.041 \\
\hline Co-Gn & 0.03 & 0.14 & 2.328 & 1.35 & 1.16 & 0.441 & 0.326 \\
\hline $\mathrm{SN}-\mathrm{OP}$ & 2.46 & 1.58 & 0.035 & 2.66 & 1.94 & 2.008 & 0.092 \\
\hline SN/GoGn & 1.55 & 1.38 & 0.614 & 0.21 & 1.02 & 0.614 & 0.053 \\
\hline Y-axis & -0.18 & 0.54 & 1.233 & 0.69 & 0.16 & 0.982 & 1.033 \\
\hline NP-FH & 0.46 & 1.15 & 0.077 & 0.96 & 0.11 & 2.907 & 0.114 \\
\hline ANB & 4.07 & 1.87 & 0.121 & -0.78 & 0.94 & 0.211 & $0.015^{*}$ \\
\hline Convexity & 5.55 & 2.34 & 0.004 & 0.73 & 3.32 & 0.304 & $0.021^{*}$ \\
\hline MP-FH & 0.93 & 1.21 & $0.005^{*}$ & 0.92 & 1.09 & 0.523 & 0.521 \\
\hline FMA & 1.62 & 1.15 & $0.011^{*}$ & 0.25 & 1.09 & 1.061 & 0.426 \\
\hline FMIA & 6.64 & 5.01 & $0.034^{*}$ & 1.02 & 0.79 & 0.534 & $0.022^{*}$ \\
\hline IMPA & -5.02 & 4.41 & 0.521 & 0.17 & 1.21 & 1.215 & $0.013^{*}$ \\
\hline Wits (mm) & 9.15 & 2.56 & 0.445 & -1.12 & 0.34 & 4.345 & $0.032^{*}$ \\
\hline Overjet (mm) & 5.23 & 1.92 & $0.032^{*}$ & -0.15 & 0.82 & 0.332 & $0.045^{*}$ \\
\hline $\mathrm{N}-\mathrm{Me}$ & 2.65 & 0.12 & $0.034^{*}$ & 2.82 & 0.45 & 1.16 & 0.081 \\
\hline ANS-Me & 3.31 & 0.61 & 0.055 & 1.75 & 0.33 & 0.996 & 0.251 \\
\hline \multicolumn{8}{|l|}{ Dental } \\
\hline U1-SN & 17.45 & 6.33 & 0.003 & 1.16 & 1.29 & 0.074 & $0.021^{*}$ \\
\hline L1-MP & 5.04 & 2.48 & $0.044^{*}$ & 2.62 & 1.51 & 0.144 & $0.034^{*}$ \\
\hline U1-NA $\left(^{\circ}\right)$ & 5.08 & 1.33 & $0.035^{*}$ & 0.94 & 1.93 & 2.235 & $0.019 *$ \\
\hline U1-NA (mm) & 0.94 & 0.49 & $0.028^{*}$ & 0.04 & 0.53 & 0.238 & $0.016^{*}$ \\
\hline L1-NB $\left(^{\circ}\right)$ & 4.32 & 1.24 & $0.036^{*}$ & 0.33 & 0.15 & 0.435 & $0.042^{*}$ \\
\hline L1-NB (mm) & 3.27 & 1.06 & $0.034^{*}$ & 0.08 & 0.22 & 2.134 & $0.025^{*}$ \\
\hline U1-L1 & 8.63 & 3.16 & $0.015^{*}$ & -1.15 & 1.22 & 1.115 & $0.018^{*}$ \\
\hline Overbite (mm) & -1.11 & 1.09 & $0.007^{*}$ & 0.01 & 0.65 & 1.06 & 0.322 \\
\hline \multicolumn{8}{|l|}{ Soft tissue } \\
\hline FCA & 8.1 & 0.7 & $0.025^{*}$ & 0.3 & 0.4 & 2.51 & $0.011^{*}$ \\
\hline NLA & 11.84 & 2.15 & 0.328 & 0.1 & 1.21 & 0.346 & $0.024^{*}$ \\
\hline UL-E (mm) & 6 & 1.4 & $0.022^{*}$ & 0.5 & 1.2 & 1.023 & $0.033^{*}$ \\
\hline LL-E (mm) & -2 & 0.5 & $0.014^{*}$ & 1 & 0.3 & 0.114 & $0.019^{*}$ \\
\hline
\end{tabular}

${ }^{*} p<0.05$ statistically significant difference

treatment time, the tooth movement was always faster than the maxilla growth in orthodontic and/or orthopedic therapy. In the present study, the increase in U1-SN in most patients was in a controllable normal range. A significant increase was found in patients with overdeveloped mandible and maxilla deficiency (overjet $-6 \mathrm{~mm}$ ). The results of teeth changes will be influenced by the patient's initial dental and skeletal characteristics, as well as the growth pattern of the upper and lower jaw bone. In the patients whose maxilla hypoplasia was mild to moderate, the result of the teeth compensation was similar to the results of the studies ${ }^{26}$ on miniplate as a skeletal anchorage for maxillary protraction.

The tooth compensation is its defect and is not expected, however, self-correction can occur with the discontinuation of the improper oral habits, as long as proper tongue and perioral myofunction and right methods of breathing are established. In the retention period, this phenomenon will be improved, and also corrected in the second stage of orthodontic treatment. The force for the frontal movement of the maxilla in this orthopedic therapy is from perioral myofunction, rather than the orthopedic device.

Consistent with the previous studies, ${ }^{27,28}$ the soft tissue profile showed significant forward growth of maxilla was observed, with a protrusion of upper lip (UL-E $+6 \mathrm{~mm}$ ) and retrusion of the lower lip (LL-E $-2 \mathrm{~mm}$ ), especially after 1-year of retention. The upper labial protrusion in the present study was caused by maxilla forward growth, rather than orthopedic force forward protraction replacement, while the lower labial retrusion was caused by the 
Table 3: The differences of lateral cephalometric measurements after treatment (ST1) and after 1-year of retention (ST2) in the study group $(n=11$ each group)

\begin{tabular}{|c|c|c|c|c|c|}
\hline \multirow[b]{2}{*}{ Parameter } & \multicolumn{2}{|c|}{ ST1 } & \multicolumn{2}{|c|}{$S T 2$} & \multirow[b]{2}{*}{$p$ value } \\
\hline & $x$ & $S D$ & $X$ & $S D$ & \\
\hline Age (years) & 8.12 & 1.3 & 9.46 & 1.2 & 0.722 \\
\hline \multicolumn{6}{|l|}{ Cranial } \\
\hline S-N & 71.06 & 1.43 & 71.28 & 1.71 & 1.332 \\
\hline \multicolumn{6}{|c|}{ Maxilla and mandible } \\
\hline SNA & 77.22 & 2.92 & 78.72 & 1.54 & $0.045^{*}$ \\
\hline ANS-PNS & 53.27 & 2.23 & 54.98 & 2.14 & 0.116 \\
\hline SN/ANS-PNS & 8.07 & 1.28 & 8.01 & 1.45 & 0.255 \\
\hline SNB & 80.08 & 2.96 & 81.52 & 2.36 & 0.614 \\
\hline SND & 82.25 & 3.23 & 83.84 & 3.76 & 0.141 \\
\hline Co-Gn & 113.26 & 3.42 & 113.43 & 3.52 & 2.677 \\
\hline SN-OP & 12.99 & 2.55 & 13.08 & 1.86 & 2.563 \\
\hline SN-GoGn & 33.11 & 5.24 & 34.46 & 287 & 0.107 \\
\hline Y-axil & 69.69 & 4.69 & 69.74 & 3.61 & 0.183 \\
\hline $\mathrm{NP}-\mathrm{FH}$ & 88.96 & 16.11 & 88.74 & 12.27 & 0.512 \\
\hline ANB & 0.28 & 0.94 & 1.91 & 1.66 & $0.013^{*}$ \\
\hline Convexity & 2.8 & 0.62 & 1.56 & 0.34 & $0.111^{*}$ \\
\hline MP-FH & 31.29 & 10.09 & 31.92 & 21.21 & 0.225 \\
\hline FMA & 25.31 & 2.09 & 26.16 & 2.33 & 0.244 \\
\hline FMIA & 80.42 & 4.79 & 78.58 & 6.22 & 0.053 \\
\hline IMPA & 76.34 & 2.21 & 89.42 & 4.38 & $0.041^{*}$ \\
\hline Wits & -4.51 & 0.34 & -5.67 & 2.56 & $0.341^{*}$ \\
\hline Overjet & 2.15 & 1.82 & 4.748 & 2.84 & $0.021^{*}$ \\
\hline $\mathrm{N}-\mathrm{Me}$ & 111 & 3.6 & 112.85 & 3.26 & 0.064 \\
\hline ANS-Me & 60.31 & 5.22 & 61.24 & 2.37 & 0.233 \\
\hline \multicolumn{6}{|l|}{ Dental } \\
\hline U1-SN & 112.75 & 6.29 & 111.26 & 5.37 & $0.047^{*}$ \\
\hline L1-MP & 76.32 & 4.5 & 77.46 & 6.56 & $0.032^{*}$ \\
\hline U1-NA $\left({ }^{\circ}\right)$ & 38.64 & 4.37 & 38.95 & 5.26 & $0.044^{*}$ \\
\hline U1-NA (mm) & 15 & 0.53 & 13.81 & 1.41 & $0.024^{*}$ \\
\hline L1-NB $\left(^{\circ}\right)$ & 15.86 & 3.95 & 17.73 & 3.37 & $0.041^{*}$ \\
\hline L1-NB (mm) & 4.81 & 0.48 & 8.08 & 1.96 & $0.015^{*}$ \\
\hline U1-L1 & 128.77 & 7.22 & 129.78 & 5.34 & $0.006^{*}$ \\
\hline Overbite & 1.37 & 1.19 & 1.68 & 1.72 & 0.182 \\
\hline \multicolumn{6}{|l|}{ Soft tissue } \\
\hline FCA & 3 & 0.7 & 4.14 & 1.6 & 0.326 \\
\hline NLA & 93.1 & 15.21 & 91.66 & 10.22 & $0.114^{*}$ \\
\hline UL-E (mm) & 0 & 1.2 & 1.02 & 1.33 & 0.336 \\
\hline LL-E (mm) & -1 & 0.3 & -1 & 0.62 & 0.434 \\
\hline
\end{tabular}

${ }^{*} p<0.05$ statistically significant difference

retroclination of the lower incisor and slow growth of the mandible. Related to the change of soft tissue, Soo and Moore ${ }^{29}$ researched lip pressures and reported that lip pressures of resting and speaking showed significant raise and adaptive response. Some other researchers emphasized the important intraoral pressure, and the pressures tongue function, caused during swallowing function are much higher than those created during rest position and phonation. Compared with the miniplate-anchored face mark studies ${ }^{30}$ in the literature, the results were similar, even although the approaches of the orthopedic therapy were different. These results proved muscle function changes bone morphology and adapts to bone growth, and also proved growth modification was sufficient for the patients to avoid orthognathic surgery after completion of growth. If the anterior seal function of a tongue crib will limit the tongue forward movement, the alterations in the maxilla and mandibular growth pattern will happen.

The advantages of the tongue crib combination are: it is without invasive surgical procedures, including the insertion, removal, and replacement of the miniplates. It is a removable appliance, which will satisfy good hygienic treatment demands. Time efficiency and convenience also are its advantages; the mean treatment period in the present study was $24 \pm 12.35$ weeks, and the estimated length of the appointments was not frequent also, once every 4 weeks. It has a facilitated laboratory technique and involves simple clinical care. 
Convenience means the full appliance is in oral without a frontal facial pull. With no elastic intermaxillary traction, the rotation of the maxilla and mandible will be less observed. The dental and facial improvement in the present study proved tongue crib combination was an effective and feasible approach for interceptive orthopedic therapy for skeletal class III malocclusion, although it had some shortcomings.

Despite the many advantages, one disadvantage should not be overlooked the compliance of the patient is a very important factor for the successful treatment, as the device is better to wear during speaking and eating. It is suggested the appliance should be used at night-time after active treatment until the achievement of the growth and development of the child. Different mandibular movement and dental changes have significantly different levels of oral function, so the clinician should be qualified and experienced to predict and prevent relapse during retention.

\section{Conclusion}

The tongue crib combination is an effective device for interceptive treating severe skeletal Angle class III malocclusion in growing patients. Although large changes have been found at the end of active treatment, the skeletal growth modification of the midface has been obtained after 1-year of retention. These results confirmed growth modification is possible and necessary. The patients and parents can be relaxed because this orthopedic treatment is an effective method that can exclude a surgery approach after growth.

\section{References}

1. Liu ZP, Li CJ, Hu HK, et al. Efficacy of short-term chin-cup therapy for mandibular growth retardation in class III malocclusion: A systematic review. Angle Orthod 2011;81(1):162-168. DOI: 10.2319/050510-244.1.

2. Baccetti T, Reyes B, Mcnamara Jr J. . Gender differences in class III malocclusion. Angle Orthod 2005;75(4):510-520.

3. Kovalenko A, Slabkovskaya A, Drobysheva N, et al. The association between the psychological status and the severity of facial deformity in orthognathic patients. Angle Orthod 2012;82(3):396-402. DOI: 10.2319/060211-363.1.

4. Jamilian A, Cannavale R, Piancino MG, et al. Methodological quality and outcome of systematic reviews reporting on orthopaedic treatment for class III malocclusion: Overview of systematic reviews. J Orthod 2016;43(2):102-120. DOI: 10.1080/14653125.2016.1190077.

5. Baccetti T, McGill JS, Franchi L, et al. Skeletal effects of early treatment of class III malocclusion with maxillary expansion and face-mask therapy. Am J Orthod Dentofacial Orthop 1998;113(3):333-343. DOI: 10.1016/S0889-5406(98)70306-3.

6. Martinez P, Bellot-Arcís C, Llamas JM, et al. Orthodontic camouflage versus orthognathic surgery for class III deformity: comparative cephalometric analysis. Int J Oral Maxillofac Surg 2017;46(4):490-495. DOI: 10.1016/j.ijom.2016.12.001.

7. Eslami S, Faber J, Fateh A, et al. Treatment decision in adult patients with class III malocclusion: surgery versus rthodontics. Prog Orthod 2018;19(1):28-33. DOI: 10.1186/s40510-018-0218-0.

8. Showkatbakhsh R, Jamilian A, Ghassemi M, et al. The effects of facemask and reverse chin cup on maxillary deficient patients. J Orthod 2012;39(2):95-101. DOI: 10.1179/1465312512Z.00000000011.

9. Westwood PV, McNamara JA, Baccetti T, et al. Long-term effects of class III treatment with rapid maxillary expansion and facemask therapy followed by fixed appliances. Am J Orthod Dentofacial Orthop 2003;123(3):306-320. DOI: 10.1067/mod.2003.44.

10. Maino G, Turci Y, Arreghini A, et al. Skeletal and dentoalveolar effects of hybrid rapid palatal expansion and facemask treatment in growing skeletal class III patients. Am J Orthod Dentofacial Orthop 2018;153(2):262-268. DOI: 10.1016/j.ajodo.2017.06.022.
11. Duggal R, Mathur V, et al. Class III - malocclusion: genetics or environment? A twins study. Indian J Soc Pedod Prev Dent 2005;23(1):27-30. DOI: 10.4103/0970-4388.16023.

12. De Clerck EEB, Swennen GRJ. Success rate of miniplate anchorage for bone anchored maxillary protraction. Angle Orthod 2011;81(6):10101013. DOI: 10.2319/012311-47.1.

13. Nienkemper $M$, Wilmes $B$, Franchi $L$, et al. Effectiveness of maxillary protraction using a hybrid hyrax-facemask combination: A controlled clinical study. Angle Orthod 2015;85(5):764-770. DOI: 10.2319/071614497.1.

14. Kircelli BH, Pektaş ZO, Uc,kan S. Orthopedic protraction with skeletal anchorage in a patient with maxillary hypoplasia and hypodontia. Angle Orthod 2006;76(1):156-163.

15. Lin Y, Guo R, Hou L, et al. Stability of maxillary protraction therapy in children with class III malocclusion: a systematic review and meta-analysis. Clin Oral Investig 2018;22(7):2639-2652. DOI: 10.1007/ s00784-018-2363-8.

16. Nascimento MHA, Araújo TM, Machado AW. Severe anterior open bite during mixed dentition treated with palatal spurs. J Clin Pedia Dent 2016;40(3):247-250. DOI: 10.17796/1053-4628-40.3.247.

17. Sayın MO, Akın E, Karacay S, et al. Initial effects of the tongue crib on tongue movements during deglutition: A cine-magnetic resonance imaging study. Angle Orthod 2006;76(3):400-405.

18. Cleall JF. Deglutition: a study of form and function. Am J Orthod 1965;51(8):566-591. DOI: 10.1016/0002-9416(65)90028-X.

19. Showkatbakhsh $R$, Toumarian $L$, Jamilian $A$, et al. The effects of face mask and tongue plate on maxillary deficiency in growing patients: a randomized clinical trial. J Orthod 2013;40(2):130-136. DOI: 10.1179/1465313312Y.0000000036.

20. Woon SC, Thiruvenkatachari B. Early orthodontic treatment for Class III malocclusion: a systematic review and meta-analysis. Am J Orthod Dentofacial Orthop 2017;151(1):28-52. DOI: 10.1016/j. ajodo.2016.07.017.

21. De Clerck HJ, Proffit WR. Growth modification of the face: a current perspective with emphasis on class III treatment. Am J Orthod Dentofac Orthop 2015;148(1):37-46. DOI: 10.1016/j.ajodo.2015.04.017.

22. Proffit WR. Muscle pressures and tooth position: north American whites and Australian aborigines. Angle Orthod 1975;45(1):1-11.

23. Slaviero T, Fernandes TMF, Oltramari-Navarro PVP, et al. Dimensional changes of dental arches produced by fixed and removable palatal cribs: A prospective, randomized, controlled study. Angle Orthod 2017;87(2):215-222. DOI: 10.2319/060116-438.1.

24. Taslan S, Biren S, Ceylanoglu C. Tongue pressure changes before, during and after crib appliance therapy. Angle Orthod 2010;80(3):533-539. DOI: 10.2319/070209-370.1.

25. Koh SD, Chung DH. Comparison of skeletal anchored facemask and tooth-borne facemask according to vertical skeletal pattern and growth stage. Angle Orthod 2014;84(4):628-633. DOI: 10.2319/060313-421.1.

26. Bozkaya E, Yu"ksel AS, Bozkaya S. Zygomatic miniplates for skeletal anchorage inorthopedic correction of class III malocclusion: a controlled clinical trial. Korean J Orthod 2017;47(2):118-129. DOI: 10.4041/kjod.2017.47.2.118.

27. Perillo L, Vitale M, Masucci C, et al. Comparisons of two protocols for the early treatment of class III dentoskeletal disharmony. Eur J Orthod 2016;38(1):51-56. DOI: 10.1093/ejo/cjv010.

28. Lee HS, Choi HM, Choi DS, et al. Bone thickness of the infrazygomatic crest area in skeletal class III growing patients: A computed tomographic study. Imaging Sci Dent 2013;43(4):261-266. DOI: 10.5624/isd.2013.43.4.261.

29. Soo ND, Moore RN. A technique for measurement of intraoral lip pressure with lip bumper therapy. Am J Orthod 1991;99(5):409-417. DOI: 10.1016/S0889-5406(05)81574-4.

30. Meyns J, Brasil DM, Mazzi-Chaves JF, et al. The clinical outcome of skeletal anchorage in interceptive treatment (in growing patients) for class III malocclusion. Int J Oral Maxillofac Surg 2018;47(8):1003-1010. DOI: 10.1016/j.ijom.2018.04.011. 